\title{
Quantifying Cardiovascular Flow Dynamics During Early Development
}

\author{
JAY R. HOVE \\ Department of Genome Science, Genome Research Institute, University of Cincinnati, Cincinnati, OH 45237
}

\begin{abstract}
The relationship between developing biologic tissues and their dynamic fluid environments is intimate and complex. Increasing evidence supports the notion that these embryonic flowstructure interactions influence whether development will proceed normally or become pathogenic. Genetic, pharmacological, or surgical manipulations that alter the flow environment can thus profoundly influence morphologic and functional cardiovascular phenotypes. Functionally deficient phenotypes are particularly poorly described as there are few imaging tools with sufficient spatial and temporal resolution to quantify most intra-vital flows. The ability to visualize biofluids flow in vivo would be of great utility in functionally phenotyping model animal systems and for the elucidation of the mechanisms that underlie flow-related mechano-sensation and transduction in living organisms. This review summarizes the major methodological advances that have evolved for the quantitative characterization of intra-vital fluid dynamics with an emphasis on assessing cardiovascular flows in vertebrate model organisms. (Pediatr Res 60: 6-13, 2006)
\end{abstract}

\section{ROLE OF FLUID FLOW IN DEVELOPMENT}

$\mathrm{I}^{\mathrm{n}}$ addition to facilitating convective transport, intra-vital fluid flows impose substantial mechanical stresses on adjacent and underlying cells. These flow-induced forces are widely acknowledged as critical to the proper development and maintenance of many aspects of biologic form and function. This is particularly true during embryogenesis where internally-derived, flow-related forces are thought to be morphogens influencing a number of key developmental processes including; symmetry determination $(1,2)$, cardiogenesis (3-5), blood vessel formation $(6,7)$, glomerulogenesis $(8)$, brain development (9), and lung development $(10,11)$. In addition to their roles during normal development, the biomechanical forces generated by aberrant intra-vital flow have been implicated as important factors in the pathogenesis of a variety of diseases in the cardiovascular (12-14), nervous (15-17), and renal $(18-20)$ systems.

The specific mechanisms by which living cells sense, transduce and respond to flow-induced stresses are only partially

Received November 16, 2005; accepted February 1, 2006.

Correspondence: Jay R. Hove, Ph.D., Department of Genome Science, Genome Research Institute, University of Cincinnati, 2180 E. Galbraith Road, Cincinnati, OH 45237; e-mail: jay.hove@uc.edu

Works from the author's laboratory are funded by the American Heart Association, the Kidney Foundation of Greater Cincinnati and the National Institutes of Health.

DOI: 10.1203/01.pdr.0000219584.22454.92 known (21-25). In vitro studies have contributed a great deal to our understanding of these signaling pathways in general, and how cardiovascular endothelial cells, the flow sensors and transducers lining the vascular walls, react to shear stress (26-29), stretch $(30,31)$, and pressure $(32,33)$. Of these, wall shear stress has received the most attention as both its magnitude and orientation are thought to play roles during vascular development. Fluid shear stresses occur within the cardiovascular system as blood flows tangentially to the surrounding vessel wall. This frictional force is defined by the product of the shear rate (derivative of velocity with respect to the vessel radius) and the dynamic viscosity of blood. To reconcile the complex velocity gradients that exist within a pulsing, flexible heart tube filled with a moving, non-Newtonian fluid we need to obtain some understanding of the cross-sectional flow profile of the vessel. With these data we are better able to determine whether the flow has had time to establish itself into the parabolic velocity profile expected for laminar flow or whether perturbations in the flow have resulted in altered cross-sectional gradients. Characterizing the magnitude and orientation of the shear forces acting at the level of the biologic flow sensors, rather than those calculated from midlumenal flow, is critically important if we are to ascertain the extent to which these biophysical forces influence cellular response.

Although in vitro studies have been important in helping to elucidate the responses of cultured endothelial cells to a variety of biophysical stresses, their utility is reduced by our inability to accurately reproduce the complexity of biologic flows and the physicochemical interconnectivity of living tissues. These limitations have led researchers in developmental biology to appreciate that in vivo mapping of biofluid flows is the critical next step if significant further progress is to be made in our understanding of intra-vital flow-structure interactions during developmental and disease processes. Despite its potential utility in dynamically characterizing many biologic systems, flow mapping efforts to date have largely focused on the developing cardiovascular system, because it

Abbreviations: CMOS, complementary metal oxide semiconductor; dpf, days post-fertilization; DPIV, digital particle image velocimetry; PC-MR, phasecontrast magnetic resonance; US, ultrasound 
appears very early in embryogenesis, is optically accessible, and exhibits a wide range of flow dynamics.

\section{HEMODYNAMICS AND CARDIAC DEVELOPMENT}

The influence of blood flow on the form of the heart, and conversely, the effect of genetically-determined form on flow, have been topics of debate for nearly a century (34-36). Goertller (37) was probably correct when he pointed out that while some aspects of cardiovascular formation are certainly pre-programmed, other areas are just as surely dependent upon the characteristics of local fluid flow. So how does the energy imparted to the blood influence cardiac morphology? Several hypotheses have been posited, including: 1) differential cellular growth due to residual stress and strain (38);2) changes in blood flow volume and pressure zones restructuring media replacement and affecting luminal diameters (39-40); 3) fluid shear rates at intra-cardiac surfaces $(41,42)$; and 4 ) blood flow leading to endothelium-mediated signals $(43,44)$.

There is a wealth of evidence suggesting that flow-induced stresses, such as the frictional shear imposed by blood flow on adjacent cardiovascular endothelial cells, can substantially influence vascular development and adaptation as well as pathogenesis of vascular disease adult organisms $(12,45-50)$. In fact, much of our current understanding about cellular responses to flow-induced forces comes from studies of the mature arterial endothelium. In such systems there is substantial evidence for multiple flow sensors $(26,51-54)$, capable of eliciting responses via MAP kinases $(55,56)$, PI3-kinase (57$59)$, protein kinase $\mathrm{C}(60), \mathrm{NF}-\kappa \mathrm{B}(61)$ and other signal transduction pathways.

Evidence that different flow regimes (e.g., steady versus pulsatile, laminar versus turbulent) can differentially regulate gene expression (62-64) attests to the subtlety with which mature cardiovascular tissues can respond to changes in blood flow-induced forces. Interestingly, many of these flowregulated genes encode products that directly regulate tissue growth and remodeling $(65,66)$ or are important transcription factors that have been linked to growth control $(67,68)$. This supports the notion that some of the same sensory transduction pathways used by mature animals may be found in developing organisms as well. Unfortunately, our understanding of the hemodynamic milieu within the developing vertebrate embryo is far from complete. The data we do have emphatically tells us that experimental disruptions of the venous return or arterial outflow during early development can lead to severe dysmorphogenesis (69-72). However, our ability to quantitatively describe these complex biologic flows within living, growing organisms is frequently limited by their small size and the relative inaccessibility of internal fluid flow environments to flow-sensing instrumentation. In the absence of reliable intra-vital flow data, discourse concerning the underlying factors responsible for both normal and pathophysiological cardiovascular development will be incomplete and the conclusions drawn from it will remain speculative. Fortunately, this problem has not gone unnoticed and, as a result, significant research effort is being expended in the develop- ment of instrumentation capable of quantifying micro-scale intra-vital flows.

\section{MEASURING INTERNAL FLUID FLOW}

The biomedical research literature is replete with imaging techniques aimed at characterizing intra-vital flows, with generally mixed results. One approach commonly used in large mammals is to physically position a flow sensor directly into, or adjacent to the flow field of interest (73-75). While this is the most direct method for obtaining quantitative flow data, the typically invasive nature of positioning a flow probe in such a manner can significantly perturb an adult system and the effect on a developing embryo may be prohibitive. Despite this difficulty, the use of surgically implanted pulsed Doppler probes in mouse and chick embryos have led to an improved understanding of developmental hemodynamics in vertebrates (76-84).

Embryonic chicks are highly amenable to this technique as they can be rotated in windowed eggs to bring the vessel of interest to a superficial position for optimal orientation of the small $(\sim 0.5 \mathrm{~mm})$ piezoelectric crystal probe. Although such probes have been used quite effectively, Doppler ultrasound (US) techniques can be confounded by moving vessel boundaries or by flow in closely adjacent vessels. As a result, great care must be taken in choosing the anatomical area to be examined. Although its temporal resolution can be quite good, spatial resolution of Doppler US is limited by the size and angular orientation of the piezoelectric crystals. In addition, signal frequency must be carefully monitored as high-intensity pulsed US has been shown to affect cardiac rhythm and aortic blood pressure in frogs (85).

In response to these issues, other, less invasive medical imaging technologies have been refined for small scale biofluids imaging in humans with potential application to small animal models as well. Phase contrast magnetic resonance (PC-MR) imaging of blood flow in humans is based on a phase shift of the magnetization when the blood flows in the direction of a magnetic field gradient (86). Partial volume errors and errors related the area to be interrogated still persist when examined on smaller scales although new algorithms are being developed to improve spatial resolution (87). Non-gated MR imaging has been used in conjunction with Doppler US for detection of slow blood flows in humans $(88,89)$, as has Orthogonal Polarization Spectral (OPS) imaging (90). Deuterium MR imaging of slow intra-ocular fluid flow has been accomplished in rabbits with $100 \mu \mathrm{m}$ spatial resolutions (91). Unfortunately, none of these approaches provide the temporal sensitivity necessary to characterize typical embryonic cardiovascular flow. MR imaging has shown great promise as an anatomical tool for assessing developmental cardiovascular defects in the mouse model (92-94). Unfortunately, the proper preparation of the embryos requires chemical fixation, eliminating the possibility of dynamic measurements of cardiovascular performance. Positron emission tomography (PET) has been adapted to detect cerebral blood flow dynamics in adult rabbits (95) but intrinsically limited spatial resolution (96) suggests limited utility on the developmental size scale. 
Perhaps the most promising new imaging technology for quantifying developmental biofluid flows is US biomicroscopy (UBM)-Doppler, a non-invasive, high-frequency echocardiography system. UBM is currently capable of achieving spatial resolutions on the order of $30 \mu \mathrm{m}$ axial and $90 \mu \mathrm{m}$ lateral with sufficient temporal resolution to make reliable velocity measurements within developing vertebrate embryos. UBM has been successfully used to examine cardiovascular morphology, dimensions and blood flow in the mouse and zebrafish embryos (97-99). A more detailed review of developmental UBM imaging can be found in this issue of Pediatric Research.

While most of these imaging modalities continue to operate well within their prescribed research niche, few possess the spatial and temporal resolution required to quantitatively characterize the cross-sectional flow profile of a developing blood vessel. As such, the development of new, more powerful imaging technologies is necessary if we are to derive the flow induced forces acting at the level of the biologic flow sensors within living organisms. Several research groups are now looking to transfer emerging fluid mechanical engineering technologies to these challenging biomedical applications.

\section{QUANTITATIVE FLOW VISUALIZATION IN ZEBRAFISH}

Ludwig Prandtl's work in the early part of the twentieth century was the beginning of the movement from passive observation of fluid flows to experimentally extracting information from them. A pioneering fluid mechanist, Prandtl suspended mica particles on the surface of moving water to qualitatively study aspects of unsteady flow (100). Recent advances in optics, lasers and computer technologies allow modern day fluid mechanists to collect detailed quantitative data about instantaneous flow velocities from the same kinds of seeded flows observed in Prandtl's time. To transfer these technologies from fluid mechanical engineering applications to the task of quantitatively mapping developmental biologic flows a tractable animal model system is needed.

The ideal animal model system should demonstrate circulatory functions characteristic of other vertebrate models and be optically accessible with modern microscopic tools. To find such a model researchers are turning to "lower vertebrate" systems (e.g., fish and frogs). The zebrafish (Danio rerio), has become an important model system for studying organo- genesis, particularly the form and function of the developing cardiovascular system (101-104). Although the single-circuit, two-chambered piscine heart cannot fully model all aspects of mammalian cardiogenesis, many fundamental developmental processes (e.g., heart tube formation, looping, valvulogenesis and septation) follow a pattern of extreme evolutionary conservation across vertebrate taxa. This affords us the opportunity to study the pathways underlying important cardiogenetic processes in zebrafish to better understand how those same processes unfold in mammals and specifically, in humans. In fact, zebrafish possess a number of life history characteristics that make them more amenable than their mammalian and avian counterparts to studies of dynamic developmental imaging. Included among these are external fertilization, small size, rapid development, optical transparence, and genetic accessibility (105).

The tissue clarity afforded by a transparent embryo greatly facilitates non-invasive optical dissection using modern confocal microscopic techniques (Fig. 1). Structural contrast can be provided by vital staining or the use of transgenic lines expressing fluorescent protein markers like green fluorescent protein (GFP) $(106,107)$. Embryos expressing the appropriate labels can then be anesthetized and easily mounted for microscopic observation (108). The zebrafish cardiovascular system begins to form early in development with pumping of blood commencing at about 1 day post-fertilization (dpf) (109). Astounding anatomical detail of the embryonic zebrafish heart and its microvasculature has now been described throughout ontogeny from microscopic observation of both fixed tissues $(4,110)$ and in living tissues after the introduction of fluorescently labeled dyes/microspheres. The latter have been used to produce exquisite micro-angiograms of the developing zebrafish vasculature, allowing us an unprecedented glimpse at the way primary and secondary blood vessels form $(111,112)$.

Functional phenotyping of cardiovascular performance began with recordings of micro-scale blood pressures within the living zebrafish $(4,110,113,114)$. Using native particles (e.g., erythrocytes, platelets) as flow markers, the first descriptions of the gross blood flow patterns in developing zebrafish were made possible. Particle displacements were used to approximate blood flow in zebrafish larvae by measuring the differential lengths of the vector shifts between two adjacent video frame fields acquired during microscopic observation (115). In addition to determining erythrocyte velocities, this technique
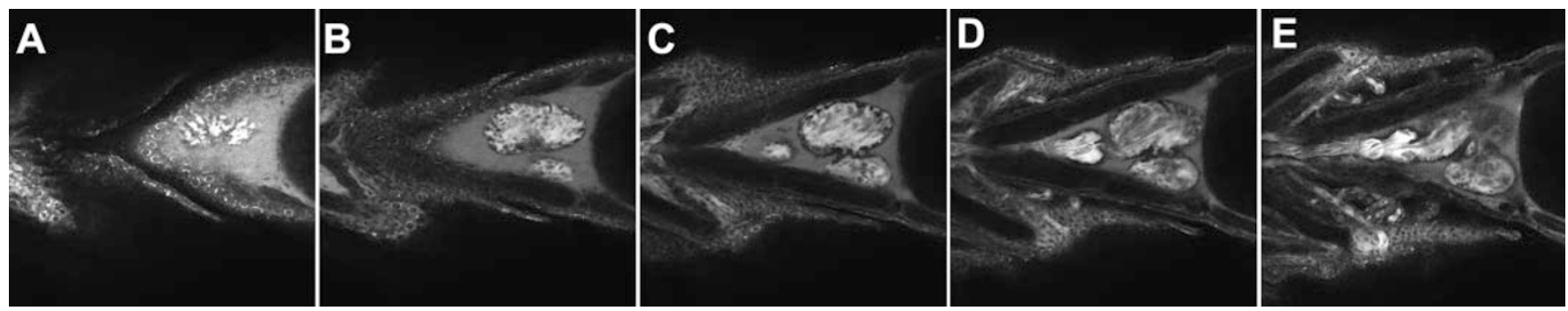

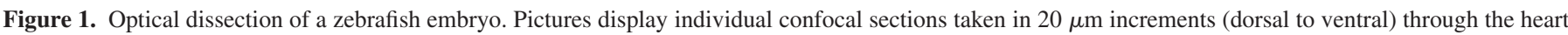

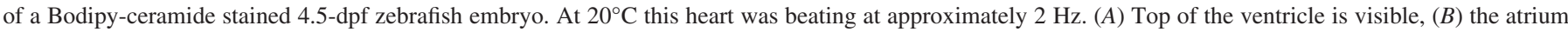

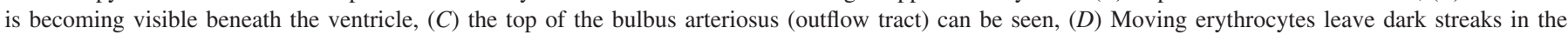
fluoresced serum making vortices and jets visible, $(E)$ High-velocity flow in the outflow tract feeds the branchial aortae. 
was an effective way to visualize their relative distribution within anatomical regions of interest. Overlays of multiple particle pathlines were used to produce reasonably good approximations of vessel inner dimensions as well. Erythrocyte tracking was also used in a recent optical analysis of blood flow in the superficial vasculature of the embryonic mouse yolk sac (116). Blood flow velocities were measured by confocally line scanning images perpendicular to the flow and measuring the vertical distortion of the circular red blood cells with respect to time. In large diameter vessels $(200 \mu \mathrm{m})$ cross-sectional flow profiles were reconstructed from erythrocyte velocity measurements and shear stresses calculated.

The increasingly widespread use of discrete particles suspended in the blood as flow tracers has hastened the introduction of sophisticated flow visualization analysis techniques to the study of intra-vital biofluids flows. Most of these methods use time-sequenced images of particle fields for either individual particle tracking or statistical descriptions of particle groups for obtaining displacement information and subsequently, velocity fields (117). From these velocity maps a number of useful force fields can be derived. One of these analytical techniques, digital particle image velocimetry (DPIV), is becoming the new technical standard for creating quantitative maps of in vivo flow environments.

\section{MAPPING DEVELOPMENTAL FLOWS WITH DPIV}

DPIV is a powerful global quantitative flow visualization method based on following groups of particles as they move through a defined space. In evaluation of external fluid flows (e.g., around the wing of a model plane), small reflective particles are used to seed the fluid (air or water) volume within which the object is suspended and are briefly illuminated as they pass through a pulsed laser sheet. Two consecutive images of the reflected particles are then acquired with a high-speed CCD camera over a short time interval and the resulting image pairs are digitally captured. Data processing is accomplished by recognizing that two sequential particle field images can together produce a shifted composite image depicting motion. A field of displacement vectors can be obtained by analyzing the movements of localized groups of particles. Mean velocity vectors are statistically determined by cross-correlation of sub-sampled regions ("interrogation windows") extracted from the two image fields (118) (Fig. 2A-B). For measuring internal flows the same general principles apply. Due to the small size of zebrafish embryos, quantitative flow visualization by DPIV requires the use of microscopic observation of the flow fields. To generate quantitative flow maps, an appropriate optical system is necessary. This system must have: 1) the proper spectral specifications to visualize particles seeded within the flow field (i.e., dependant on the particle label); 2) an image recording system of sufficient quantum efficiency and speed to capture the flows of interest under a variety of experimental conditions (e.g., high-speed or fluorescently labeled flows), and 3) the ability to collect 3-D information over time with the necessary acquisition tools and software for subsequent flow pattern analysis.
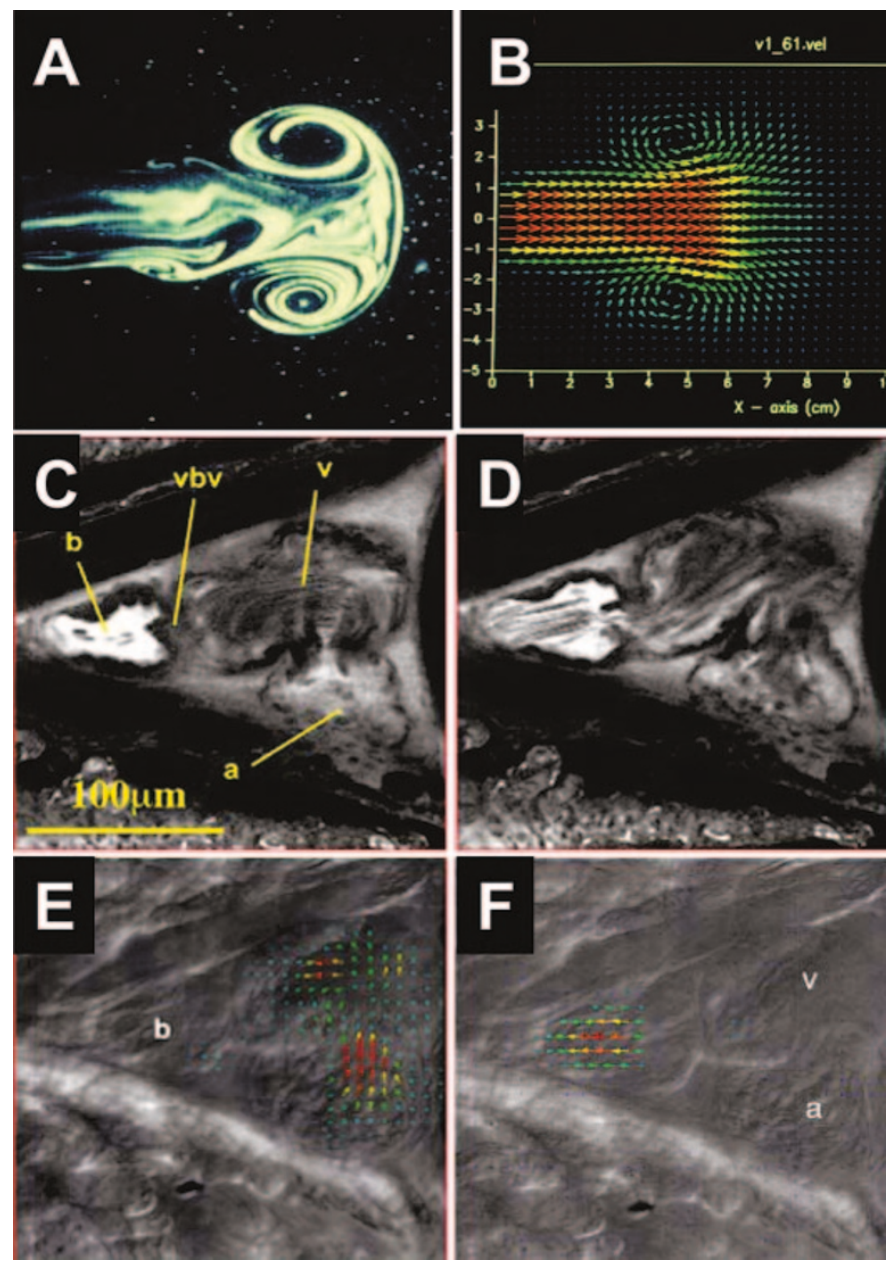

Figure 2. DPIV analysis of fluid flow. (A) A typical 2-D plane of a fluid jet seeded with reflective particles is illuminated with by a pulsed laser. Note the $2-\mathrm{cm}$ diameter central jet and the way it is rolling up into a torus. (B) Velocity vector field representing the cross-section from A. The warmer (e.g., red) vectors indicate higher velocity flow and cooler vectors (e.g., blue) low velocity flow. $(C-D)$ High-velocity blood flow generated by a 4.5 -dpf embryonic zebrafish heart. Pictures are characteristic confocal sections from a single time series of Bodipy-ceramide stained embryos. (C) Atrial systole and ventricular filling. $(D)$ Ventricular systole leading to refilling of the atrium. $(E-F)$ Overlay of DPIV velocity fields from real-time, high-speed imaging. (E) Complex flow in the filling ventricle with higher velocity flow at the atrio-ventricular constriction. $(F)$ High-velocity trans-aortic jet through the ventriculo-bulbal valve during systole. a, atrium; b, bulbus arteriosus; v, ventricle; vbv, ventriculo-bulbal valve.

Quantitative characterization of any flow field by DPIV is predicated on the proper seeding of the fluid with markers of the appropriate type and density such that the motions of those particles accurately reflect the spatial and temporal patterns of the flow. This is particularly true of biologic flow fields which are rife with confounding factors that may negatively influence the fidelity with which the particles represent the fluid flow. It is critical for the tracer particles to mimic the local flow conditions as closely as possible for accurate flow visualization by DPIV.

A number of factors should be considered when choosing particles for in vivo DPIV use including particle size, density, surface properties, contrast, and biologic reactivity/toxicity issues. The diameter of the tracer particles is of primary 
importance as an individual particle must be large enough to be discretely identified from other particles, yet small enough to follow local flows with high precision. Recent in vivo particle tracking studies have used native particles to map flow fields within the superficial rat $(119,120)$ and rabbit (121) mesentery vessels, and in the developing zebrafish heart (71) (Fig. 2). In this latter study, high-speed erythrocyte tracking shed new insight into the dynamic nature of developmental intra-cardiac flow on the micro-scale. Forces far in excess of those predicted for fluid flow at Reynold's numbers (inertial forces/viscous forces) much less than one were measured bringing into question the importance of their magnitude in shaping both the normal form and function of the developing heart. In the absence of such stimulation, development may proceed abnormally (Fig. 3). In addition, observation of the mechanics of early cardiac valve function and the mechanisms responsible for minimizing backflow before they are fully functional were elucidated (122). While wholly natural to the organism, red blood cells are likely too large $(\sim 7-10 \mu \mathrm{m})$ to provide the seeding densities needed for optimal statistical cross-correlation and spatial resolution in smaller vessels.

Future research in intra-vital DPIV is likely to use commercially manufactured microspheres as tracer particles. Microspheres are currently available in a size range of about 0.02 $200 \mu \mathrm{m}$ diameter and may possess a number of other useful properties. Typically manufactured from polystyrene ( $\rho \sim 1050$ $\mathrm{kg} \mathrm{m}^{-3}$ ), microspheres are designed to be neutrally buoyant in typical biofluids $\left(\rho=1000-1066 \mathrm{~kg} \mathrm{~m}^{-3}\right)$. This is important as the particle density should closely match the density of the surrounding fluid to prevent floating or settling, both of which can lead to measurement error. The tendency of the tracer particles to adhere to one another or to adjacent surfaces (e.g., other cells or vessel walls) is also an undesirable yet common difficulty arising during in vivo measurements of flow. To

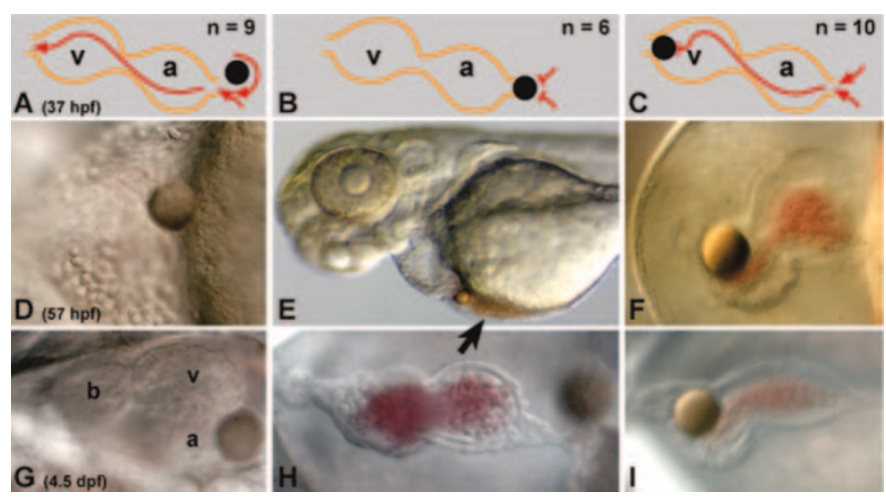

Figure 3. Reduced blood flow-induced forces induce dysmorphogenesis. Glass beads $(50 \mu \mathrm{m})$ were surgically positioned at $37 \mathrm{hpf}(A)$ adjacent to the heart inflow without blocking flow, $(B)$ within the inflow effectively stopping venous return to the heart or, $(C)$ within the ventricular outflow, preventing blood from exiting the heart. Blockages were checked after $20 \mathrm{~h}(D-F)$ and heart development was accessed at approximately $100 \mathrm{hpf}(G-I)$. Note the effectiveness of the block demonstrated by a lack of erythrocytes in the ventricle and their massive accumulation upstream of the bead in the atrium $(E$, arrowhead). Development was normal in surgical control experiment $(G)$ but severely disrupted in flow-compromised treatments regardless of blockage location $(H, I)$. Outflow tract development was greatly reduced or absent entirely and neither looping nor valvulogenesis occurred in flow-block experiments. a, atrium; $b$, bulbus; $v$, ventricle. avoid particle aggregation, tracers can be treated with surfactants or have their surface properties altered. One example is the addition of a high density of carboxylic acids to the sphere surfaces. The resulting negative surface charges increases hydrophilicity, helping to keep the tracers suspended within the fluid flow. In addition to the properties of the tracers themselves the seeding density, or the number of particles per unit area being visualized, is one of the most important factors for obtaining good statistical correlations during the DPIV data analysis (123). The optimal scenario is one in which the tracers are sufficiently small to follow the fluid flow with great fidelity, yet are large enough that they can be resolved individually with available optics (Fig. 4). A recent in vitro demonstration of the potential power DPIV in measuring fluid dynamics resulted in extremely high spatial $(9 \mu \mathrm{m} \times 2 \mu \mathrm{m})$ and temporal $(6000 \mathrm{~Hz})$ resolution of a simulated biologic flow field (124). This level of performance isn't currently possible for in vivo applications as under the low light conditions of typical vital fluorescence microscopy even the best back-thinned CCDs, CMOS sensors and electron multiplying technologies have greatly reduced temporal resolution (up to $\sim 100$ frames $\mathrm{s}^{-1}$ ). Fortunately, most biologic applications using DPIV do not require such extreme performance from their optical system.

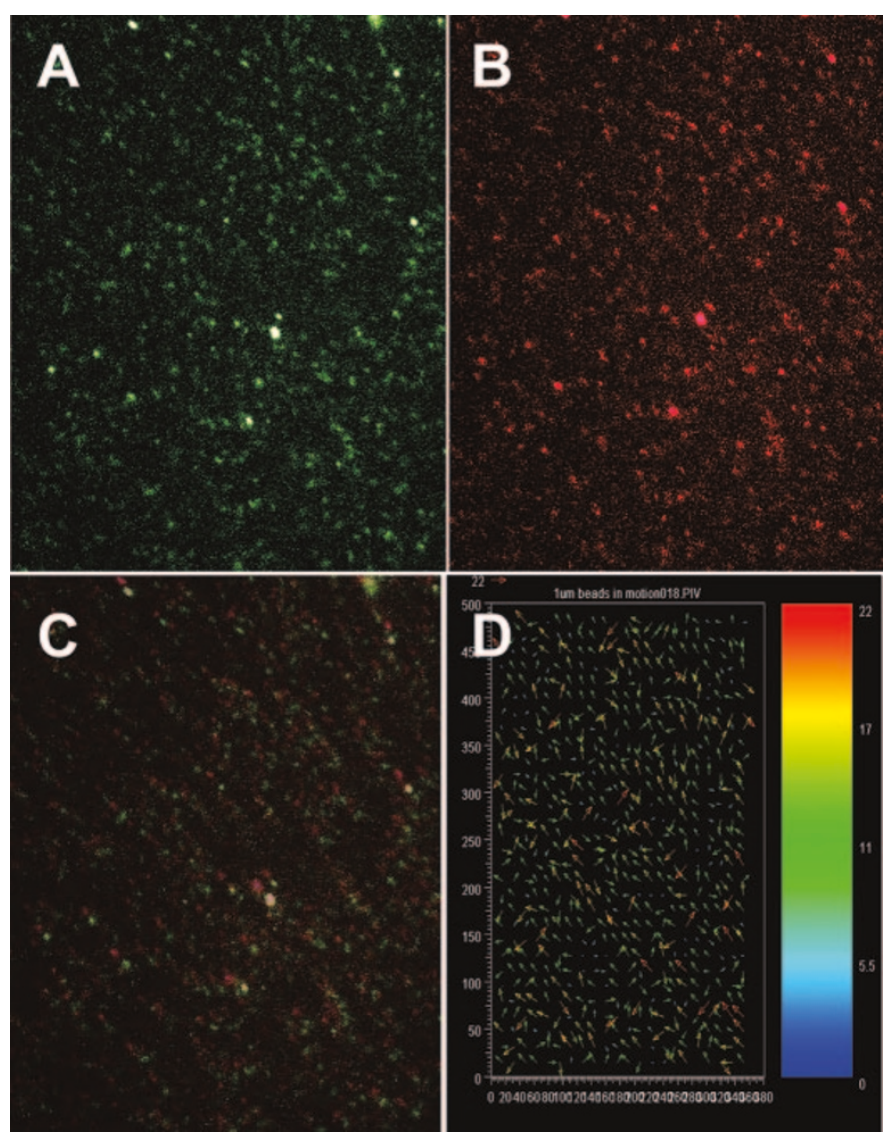

Figure 4. High-speed confocal imaging and DPIV analysis of $1 \mu \mathrm{m}$ pseudocolored fluorescent microspheres. $(A)$ Seeded flow field at time $=\mathrm{t}_{0}$. $(B)$ Displaced particles time $=\mathrm{t}_{0}+\Delta \mathrm{t}$. $(C)$ Overlay of displacement fields allows visualization of a linear shift from the lower right to upper left of the image. (D) Velocity vector field generated by DPIV analysis confirms local flow directions and magnitude. The warmer (e.g., red) vectors indicate higher velocity flow and cooler vectors (e.g., blue) low-velocity flow. 
DPIV analysis of intra-vital fluid flows is a recent practice, but a number of interesting biologic phenomena have already been observed in these early experiments. For example, in vivo velocity distributions across the superficial microvessels of mouse cremaster muscle have been characterized by DPIV (125). A fascinating result of this work is the predictability of the hydrodynamically relevant thickness of the glycocalyx layer lining the blood vessels. These data may be useful in future studies which evaluate the integrity of the vasoprotective glycocalyx layer during atherogenesis. We may also gain a better understanding of the resistive forces faced by rolling leukocytes during inflammatory responses (126). Intra-vital use of DPIV outside of the cardiovascular system is now beginning as well with the study of fluid motions within the bells of jellyfish and the buccal cavities of fish. These kinds of innovative applications of in vivo DPIV will provide additional insight into the dynamic flow-structure interactions involved in the development of locomotory and feeding mechanisms $(127,128)$.

\section{REFERENCES}

1. Cartwright JH, Piro O, Tuval I 2004 Fluid-dynamical basis of the embryonic development of left-right asymmetry in vertebrates. Proc Natl Acad Sci USA101:7234-7239

2. Okada Y, Takeda S, Tanaka Y, Belmonte JC, Hirokawa N 2005 Mechanism of nodal flow: a conserved symmetry breaking event in left-right axis determination. Cell 121:633-644

3. Hogers B, DeRuiter MC, Gittenberger-de Groot AC, Poelmann RE 1997 Unilateral vitelline vein ligation alters intracardiac blood flow patterns and morphogenesis in the chick embryo. Circ Res 80:473-481

4. Hu N, Sedmera D, Yost J, Clark EB 2000 Structure and function of the developing zebrafish heart. Anat Rec 260:148-157

5. Berdougo E, Coleman H, Lee DH, Stainier DY, Yelon D 2003 Mutation of weak atrium/atrial myosin heavy chain disrupts atrial function and influences ventricular morphogenesis in zebrafish. Development130:6121-6129

6. Takahashi M, Ishida T, Traub O, Corson MA, Berk BC 1997 Mechanotransduction in endothelial cells: temporal signaling events in response to shear stress. J Vasc Res 34:212-219

7. Seki T, Yun JH, Oh SP 2003 Arterial endothelium-specific activin receptor-like kinase 1 expression suggests its role in arterialization and vascular remodeling. Circ Res 93:682-689

8. Serluca FC, Drummond IA, Fishman MC 2002 Endothelial signaling in kidney morphogenesis: a role for hemodynamic forces. Curr Biol 12:492-497

9. Kramer-Zucker AG, Olale F, Haycraft CJ 2005 Cilia-driven fluid flow in the zebrafish pronephros, brain and Kupffer's vesicle is required for normal organogenesis. Development 132:1907-1921

10. Liu M, Qin Y, Liu J, Tanswell AK, Post M 1996 Mechanical strain induces pp60src activation and translocation to cytoskeleton in fetal rat lung cells. J Biol Chem 271:7066-7071

11. Del Riccio V, van Tuyl M, Post M 2004 Apoptosis in lung development and neonatal lung injury. Pediatr Res 55:183-189

12. Langille BL, Ojha M 1997 Blood flow dynamics, atherosclerosis and bypass graft failure. Trends Cardiovasc Med 7:111-118

13. Feldman CL, Ilegbusi OJ, Hu ZJ, Nesto R, Waxman S, Stone PH 2002 Determination of in vivo velocity and endothelial shear stress patterns with phasic flow in human coronary arteries: a methodology to predict progression of coronary atherosclerosis. Am Heart J 143:931-939

14. Wasserman SM, Topper JN 2004 Adaptation of the endothelium to fluid flow: in vitro analyses of gene expression and in vivo implications. Vasc Med 9:35-45

15. Bateman GA 2004 The role of altered impedance in the pathophysiology of normal pressure hydrocephalus, Alzheimer's disease and syringomyelia. Med Hypotheses 63. 980-985

16. Chang HS, Nakagawa H 2004 Theoretical analysis of the pathophysiology of syringomyelia associated with adhesive arachnoiditis. J Neurol Neurosurg Psychiatry $75: 754-757$

17. Chang HS, Joko M, Matsuo N, Kim SD, Nakagawa H 2005 Subarachnoid pressure-dependent change in syrinx size in a patient with syringomyelia associated with adhesive arachnoiditis - case report. J Neurosurg Spine 2:209-214

18. Nauli SM, Alenghat FJ, Luo Y, Williams E, Vassilev P, Li X, Elia AE, Lu W, Brown EM, Quinn SJ, Ingber DE, Zhou J 2003 Polycystins 1 and 2 mediate mechanosensation in the primary cilium of kidney cells. Nat Genet 33:129-137

19. Forman JR, Qamar S, Paci E, Sandford RN, Clarke J 2005 The remarkable mechanical strength of polycystin-1 supports a direct role in mechanotransduction. J Mol Biol 349:861-871
20. Simons M, Gloy J, Ganner A, Bullerkotte A, Bashkurov M, Kronig C, Schermer B, Benzing T, Cabello OA, Jenny A, Mlodzik M, Polok B, Driever W, Obara T, Walz G 2005 Inversin, the gene product mutated in nephronophthisis type II, functions as a molecular switch between Wnt signaling pathways. Nat Genetics 37:537-543

21. Davies PF 1995 Flow-mediated endothelial mechanotransduction. Physiol Rev 75:519-560

22. Wang N, Butler JP, Ingber DE 1993 Mechanotransduction across the cell surface and through the cytoskeleton. Science 260:1124-1127

23. Shyy JY, Chien S 2002 Role of integrins in endothelial mechanosensing of shear stress. Circ Res 91:769-775

24. Fisher AB, Al-Mehdi AB, Manevich Y 2002 Shear stress and endothelial cell activation. Crit Care Med 30:S192-S197

25. Cleaver O, Melton DA 2003 Endothelial signaling during development. Nat Med 9:661-668

26. Kano Y, Katoh K, Fujiwara K 2000 Lateral zone of cell-cell adhesion as the major fluid shear stress related signal transduction site. Circ Res 86:425-433

27. Lee AA, Graham DA, Dela Cruz S, Ratcliffe A, Karlon WJ 2002 Fluid shear stress-induced alignment of cultured vascular smooth muscle cells. J Biomech Eng $124: 37-43$

28. Masuda H, Kawamura K, Nanjo H, Sho E, Komatsu M, Sugiyama T, Sugita A, Asari Y, Kobayashi M, Ebina T, Hoshi N, Singh TM, Xu C, Zarins CK 2003 Ultrastructure of endothelial cells under flow alteration. Microsc Res Tech 60:2-12

29. Lehoux S, Tedgui A 2004 Shear and signal transduction in the endothelial cell. Med Sci 20:551-556

30. Trepat X, Grabulosa M, Puig F, Maksym GN, Navajas D, Farre R 2004 Viscoelasticity of human alveolar epithelial cells subjected to stretch. Am J Physiol Lung Cell Mol Physiol 287:L1025-L1034

31. Katsumi A, Naoe T, Matsushita T 2005 Integrin activation and matrix binding mediate cellular responses to mechanical stretch. J Biol Chem 280:16546-16549

32. Spurrell BE, Murphy TV, Hill MA 2003 Intraluminal pressure stimulates MAPK phosphorylation in arterioles: temporal dissociation from myogenic contractile response. Am J Physiol Heart Circ Physiol 285:H1764-H1773

33. Lucchesi PA, Sabri A, Belmadani S 2004 Involvement of metalloproteinases 2/9 in epidermal growth factor receptor transactivation in pressure-induced myogenic tone in mouse mesenteric resistance arteries. Circulation 110:3587-3593

34. Roux W 1895 Gesammelte Abhandlungen über Entwickelunsmechanik der Organismen. In: Essays on the Mechanics of Development of Organisms, $2^{\text {nd }}$ ed. Leipzig, Engelmann

35. Spitzer A 1923 Uber den bauplan des normalen und missbildeten herzens. Versuch einer phylogenetischen theorie. Virchows Arch Pathol Anat Physiol Klin Med 243:81-272

36. Pernkopf E, Wirtinger W 1933 Die Transposition der herzostien-ein Versuch der erklärund dieser Erscheinung. Z Anat 100:563-711

37. Goertller K 1970 Glass model experiments of embryonic human hearts. In: Jaffee OC (ed) Cardiac Development with Special Reference to Human Heart Disease. Dayton Press, Dayton, OH, pp 29-43.

38. Taber LA, Hu N, Pexieder T, Clark EB, Keller BB 1993 Residual strain in the ventricle of the stage 16-24 chick-embryo. Circ Res 72:455-462

39. Folkow B 1956 Structural myogenic, humoral and nervous factors controlling peripheral resistance. In: Harington M (ed) Hypotensive Drugs. Pergamon Press, London, pp 163-174

40. Buus NH, Kahr O, Mulvany MJ 1999 Effects of short- and long-term heart failure on small artery morphology and endothelial function in the rat. $\mathrm{J}$ Cardiovasc Pharmacol 34:34-40

41. Mulvany MJ 1992 Determinants of vascular structure. J Cardiovasc Pharmacol 19:S1-S6

42. Pourageaud F, De Mey JG 1997 Structural properties of rat mesenteric small arteries after 4-wk exposure to elevated or reduced blood flow. Am J Physiol 273:H1699-H1706

43. Griffith TM, Edwards DH, Davies RL, Harrison TJ, Evans KT 1987 EDRF coordinates the behaviour of vascular resistance vessels. Nature 329:442-445

44. Pohl U, Dezsi L, Simon B, Busse R 1987 Selective inhibition of endotheliumdependent dilation in resistance-sized vessels in vivo. Am J Physiol 253:H234$\mathrm{H} 239$

45. Langille BL 1995 Blood flow-induced remodeling of the artery wall. In: Bevan JA, Kaley G, Rubanyi GM (eds) Flow-Dependent Regulation of Vascular Function. Oxford University Press, New York, pp 277-299.

46. Langille BL, O'Donnell F 1986 Reductions in arterial diameter produced by chronic decreases in blood flow are endothelium-dependent. Science 231:405-407

47. Topper JN, Gimbrone MA 1999 Blood flow and vascular gene expression: fluid shear stress as a modulator of endothelial phenotype. Mol Med Today 5:40-46

48. Di Stephano I, Koopmans DR, Langille BL 1998 Modulation of arterial growth of the rabbit carotid artery associated with experimental elevation of blood flow. J Vasc Res 35:1-7

49. Wong LC, Langille BL 1996 Developmental remodeling of the internal elastic lamina of rabbit arteries: effect of blood flow. Circ Res 78:799-805

50. Korshunov VA, Berk BC 2003 Flow-induced vascular remodeling in the mouse: a model for carotid intima-media thickening. Arteriolscl Throm Vasc Biol 23:21852191

51. Chen KD, Li YS, Kim M, Li S, Yuan S, Chien S, Shyy JY 1999 Mechanotransduction in response to shear stress. Roles of receptor tyrosine kinases, integrins, and Shc. J Biol Chem 274:18393-18400

52. Olesen SP, Clapham DE, Davies PF 1988 Haemodynamic shear stress activates $\mathrm{K}+$ current in vascular endothelial cells. Nature 331:168-170 
53. Gudi SR, Clark CB, Frangos JA 1996 Fluid flow rapidly activates G proteins in human endothelial cells. Involvement of $\mathrm{G}$ proteins in mechanochemical signal transduction. Circ Res 79:834-839

54. Malek AM, Jiang L, Lee I, Sessa WC, Izumo S, Alper SL 1999 Induction of nitric oxide synthase mRNA by shear stress requires intracellular calcium and G-protein signals and is modulated by PI3 kinase. Biochem Biophys Res Commun 254:231242

55. Takahashi M, Berk BC 1996 Mitogen-activated protein kinase (ERK1/2) activation by shear stress and adhesion in endothelial cells. Essential role for a herbimycinsensitive kinase. J Clin Invest 98:2623-2631

56. Azuma N, Kito H, Ikeda M, Akasaka N, Sasajima T, Sumpio BE 2001 p38 alpha MAP kinase regulates morphological changes induced by fluid shear stress. Am J Physiol Heart Circ Physiol 280:H189-H197

57. Go YM, Park H, Maland MC, Darley-Usmar VM, Stoyanov B, Wetzker R, Jo H 1998 Phosphatidylinositol 3-kinase gamma mediates shear stress-dependent activation of JNK in endothelial cells. Am J Physiol 275:H1898-H1904

58. Dimmeler S, Fleming I, Fisslthaler B, Hermann C, Busse R, Zeiher AM 1999 Activation of nitric oxide synthase in endothelial cells by Akt-dependent phosphorylation. Nature 399:601-605

59. Dimmeler S, Assmus B, Hermann C, Haendeler J, Zeiher AM 1998 Fluid shear stress stimulates phosphorylation of Akt in human endothelial cells: involvement in suppression of apoptosis. Circ Res 83:334-341

60. Kuchan MJ, Frangos JA 1993 Shear stress regulates endothelin-1 release via protein kinase C and cGMP in cultured endothelial cells. Am J Physiol 264:H150H156

61. Khachigian LM, Resnick N, Gimbrone MA, Collins T 1995 Nuclear factor-kappa $\mathrm{B}$ interacts functionally with the platelet-derived growth factor B-chain shear-stress response element in vascular endothelial cells exposed to fluid shear stress. J Clin Invest 96:1169-1175

62. Lum RM, Wiley LM, Barakat AI 2000 Influence of different forms of fluid shear stress on vascular endothelial TGF-beta 1 mRNA expression. Int J Mol Med 5:635-641

63. Lieu DK, Pappone PA, Barakat AI 2004 Differential membrane potential and ion current responses to different types of shear stress in vascular endothelial cells. Am J Physiol Cell Physiol 286:C1367-1375

64. Barbee KA 2002 Role of subcelluar shear-stress distributions in endothelial cell mechanotransduction. Ann Biomed Eng 30:472-482

65. Topper JN, Cai J, Falb D, Gimbrone MA 1996 Identification of vascular endothelial genes differentially responsive to fluid mechanical stimuli: cyclooxygenase-2, manganese superoxide dismutase, and endothelial cell nitric oxide synthase are selectively up-regulated by steady laminar shear stress. Proc Natl Acad Sci USA 93:10417-10422

66. Braddock M, Schwachtgen JL, Houston P, Dickson MC, Lee MJ, Campbell CJ 2000 Fluid shear stress modulation of gene expression in endothelial cells. News Physiol Sci 13:241-246

67. Schwachtgen JL, Houston P, Campbell C, Sukhatme V, Braddock M 1998 Fluid shear stress activation of egr-1 transcription in cultured human endothelial and epithelial cells is mediated via the extracellular signal-related kinase $1 / 2$ mitogenactivated protein kinase pathway. J Clin Invest 101:2540-2549

68. Khachigian LM, Anderson KR, Halnon NJ, Gimbrone MAJr., Resnick N, Collins T 1997 Egr-1 is activated in endothelial cells exposed to fluid shear stress and interacts with a novel shear-stress-response element in the PDGF A-chain promoter. Arterioscler Thromb Vasc Biol 17:2280-2286

69. Hogers B, DeRuiter MC, Gittenberger-de Groot AC, Poelmann RE 1999 Extraembryonic venous obstructions lead to cardiovascular malformations and can be embryolethal. Cardiovasc Res 41:87-99

70. Sedmera D, Pexieder T, Tychterova V, Hu N, Clark EB 1999 Remodeling of chick embryonic ventricular myoarchitecture under experimentally changed loading conditions. Anat Rec 254:238-252

71. Hove JR, Köster RW, Forouhar A, Acevedo-Bolton G, Fraser SE, Gharib M 2003 Intracardiac fluid-forces are an essential epigenetic factor for embryonic cardiogenesis. Nature 421:172-177

72. Miller CE, Wong CL, Sedmera D 2003 Pressure overload alters stress-strain properties of the developing chick heart. Am J Physiol Heart Circ Physiol 285:H1849-H1856

73. Tokano T, Bach D, Chang J, Davis J, Souza JJ, Zivin A, Knight BP, Goyal R, Man KC, Morady F, Strickberger SA 1998 Effect of ventricular shock strength on cardiac hemodynamics. J Cardiovasc Electrophysiol 9:791-797

74. Rusk RA, Li XN, Mori Y, Irvine T, Jones M, Zetts AD, Kenny A, Sahn DJ 2002 Direct quantification of transmitral flow volume with dynamic 3-dimensional digital color Doppler: a validation study in an animal model. J Am Soc Echocardiogr 15:55-62

75. Di Giantomasso D, May CN, Bellomo R 2003 Vital organ blood flow during hyperdynamic sepsis. Chest 124:1053-1059

76. Keller BB, MacLennan MJ, Tinney JP, Yoshigi M 1996 In vivo assessement of cardiovascular dimensions and function in day -10.5 to -14.5 mouse embryos. Circ Res 79:247-255

77. MacLennan MJ, Keller BB 1999 Umbilical arterial blood flow in the mouse embryo during development and following acutely increased heart rate. Ultrasound Med Biol 25:361-370

78. Clark EB, Hu N 1982 Developmental hemodynamic changes in the chick embryo from Stage 18-27. Circ Res 51:810-815

79. Wispe J, Hu N, Clark EB 1983 Effect of environmental hypothermia on dorsal aortic blood flow in the chick embryo, stages 18-24. Pediatr Res 17:945-948
80. Nakazawa M, Clark EB, Hu N, Wispe J 1985 Effect of environmental hypothermia on vitelline artery blood pressure and vascular resistance in the stage 18,21 , and 24 chick embryo. Pediatr Res 19:651-654

81. Dunnigan A, Hu N, Benson DW, Clark EB 1987 Effect of heart rate increase on dorsal aortic flow in the stage 24 chick embryo. Pediatr Res 22:442-444

82. Benson DW, Hughes SF, Hu N, Clark EB 1989 Effect of heart rate increase on dorsal aortic flow befor and after volume loading in the stage 24 chick embryo. Pediatr Res 26:438-441

83. Hu N, Clark EB 1989 Hemodynamics of the stage 12 to stage 29 chick embryo. Circ Res 65:1665-1670

84. Hu N, Ngo TD, Clark EB 1996 Distribution of blood flow between embryo and vitelline bed in the stage 18, 21 and 24 chick embryo. Cardiovasc Res 31:E127E13

85. Dalecki D, Keller BB, Raeman CH, Carstensen EL 1993 Effects of pulsed ultrasound on the frog heart: I. Thresholds for changes in cardiac rhythm and aortic pressure. Ultrasound Med Biol 19:385-390

86. Seitz J, Strotzer M, Wild T, Nitz WR, Volk M, Lenhart M, Feuerbach S 2001 Quantification of blood flow in the carotid arteries. Comparison of Doppler ultrasound and three different phase-contrast magnetic resonance imaging sequences. Invest Radiol 36:642-647

87. Hoogeveen RM, Bakker CJ, Viergever MA 1999 MR phase-contrast flow measurement with limited spatial resolution in small vessels: value of model-based image analysis. Magn Reson Med 41:520-528

88. Auriti A, Cianfrocca C, Pristipino C, Greco S, Galeazzi M, Guido V, Santini M 2003 Improving feasibility of posterior descending coronary artery flow recording by transthoracic Doppler echocardiography. Eur J Echocardiogr 4:214-220

89. Hata N, Wada T, Kashima K, Okada Y, Unno N, Kitagawa M, Chiba T 2005 Non-gated fetal MRI of umbilical blood flow in an acardiac twin. Pediatr Radiol 35:826-829

90. Genzel-Boroviczény O, Strötgen J, Harris AG, Messmer K, Christ F 2002 Orthogonal polarization spectral imaging (OPS): a novel method to measure the microcirculation in term and preterm infants transcutaneously. Pediatr Res 51:386-391

91. Obata T, Ikehira H, Koga M, Yoshida K, Kimura F, Tateno Y 1995 Deuterium magnetic resonance imaging of rabbit eye in vivo. Magn Reson Med 33:569-572

92. Smith BR, Johnson GA, Groman EV, Linney E 1994 Magnetic resonance microscopy of mouse embryos. Proc Natl Acad Sci USA 91:3530-3533

93. Smith BR 2001 Magnetic resonance microscopy in cardiac development. Microsc Res Tech 52:323-330

94. Schneider JE, Bhattacharya S 2004 Making the mouse embryo transparent: identifying developmental malformations using magnetic resonance imaging. Birth Defects Res C Embryo Today 72:241-249

95. Oku N, Kitagawa K, Imaizumi M, Takasawa M, Piao R, Kimura Y, Kajimoto K, Hori M, Hatazawa J 2005 Hemodynamic influences of losartan on the brain in hypertensive patients. Hypertens Res 28:43-49

96. Stickel JR, Cherry SR 2005 High-resolution PET detector design: modeling components of intrinsic spatial resolution. Physics Med Biol 50:179-195

97. Phoon CK, Turnbull DH 2003 Ultrasound biomicroscopy-Doppler in mouse cardiovascular development. Physiol Genomics 14:3-15

98. Phoon CK, Ji RP, Aristizabal O, Worrad DM, Zhou B, Baldwin HS, Turnbull DH 2004 Embryonic heart failure in NFATc1(-/-) mice - novel mechanistic insights from in utero ultrasound biomicroscopy. Circ Res 95:92-99

99. Zhou Y-Q, Zhu Y, Bishop J, Davidson L, Henkelman RM, Bruneau BG, Foster FS 2005 Abnormal cardiac inflow patterns during postnatal development in a mouse model of Holt-Oram syndrom. Am J Physiol Heart Circ Physiol 289:H992-H1001

100. Prandtl L 1905 Über Flüssigkeitsbewegung bei sehr kleiner Reibung. In: Verhandlungen des III. Internatioinalen Mathematiker-Kongresses, Leipzig, Heidelberg, pp 404-491.

101. Stainier DY, Fishman MC 1994 The zebrafish as a model system to study cardiovascular development. Trends Cardiovasc Med 4:207-212

102. Weinstein BM, Fishman MC 1996 Cardiovascular morphogenesis in zebrafish. Cardiovasc Res 31:E17-E24

103. Warren KS, Fishman MC 1998 Physiological genomics: mutant screens in zebrafish. Am J Physiol 275:H1-H7

104. Yelon D, Stainier DY 1999 Patterning during organogenesis: genetic analysis of cardiac chamber formation. Semin Cell Dev Biol 10:93-98

105. Hove JR 2004 In vivo biofluid dynamic imaging in the developing zebrafish. Birth Defects Res C Embryo Today 72:277-289

106. Köster RW, Fraser SE 2001 Tracing transgene expression in living zebrafish embryos. Dev Biol 233:329-346

107. Yu YA, Oberg K, Wang G, Szalay AA 2003 Visualization of molecular and cellular events with green fluorescent proteins in developing embryos: a review. Luminescence $18: 1-18$

108. Westerfield M 2000 The Zebrafish Book. A Guide for the Laboratory Use of Zebrafish (Danio rerio), $4^{\text {th }}$ ed.. University of Oregon Press, Eugene, OR

109. Fishman MC, Chien KR 1997 Fashioning the vertebrate heart: earliest embryonic decisions. Development 124:2099-2117

110. Hu N, Yost J, Clark EB 2001 Cardiac morphology and blood pressure in the adult zebrafish. Anat Rec 264:1-12

111. Lawson ND, Weinstein BM 2002 In vivo imaging of embryonic vascular development using transgenic zebrafish. Dev Biol 248:307-318

112. Isogai S, Lawson ND, Torrealday S, Horiguchi M, Weinstein BM 2003 Angiogenic network formation in the developing vertebrate trunk. Development 130:52815290

113. Pelster B, Burggren WW 1996 Disruption of hemoglobin oxygen transport does not impact oxygen-dependent physiological processes in developing embryos of zebra fish (Danio rerio). Circ Res 79:358-362 
114. Kopp R, Schwerte T, Pelster B 2005 Cardiac performance in the zebrafish breakdance mutant. J Exp Biol 208:2123-2134

115. Schwerte T, Pelster B 2000 Digital motion analysis as a tool for analyzing the shape and performance of the circulatory system in transparent animals. J Exp Biol 203:1659-1669

116. Jones EAV, Baron MH, Fraser SE, Dickinson ME 2004 Measuring hemodynamic changes during mammalian development. Am J Physiol Heart Circ Physiol 287:H1561-H1569

117. Gharib M, Pereira F, Dabiri D, Hove JR, Modarress D 2002 Quantitative flow visualization: toward a comprehensive flow diagnostic tool. Integr Comp Biol 42:964-970

118. Willert CE, Gharib M 1991 Digital particle image velocimetry. Exp Fluids 10:181193

119. Sugii Y, Nishio S, Okamoto K 2002 In vivo PIV measurement of red blood cell velocity field in microvessels considering mesentery motion. Physiol Meas 23:403416

120. Nakano A, Sugii Y, Minamiyama M, Niimi H 2003 Measurement of red cell velocity in microvessels using particle image velocimetry (PIV). Clin Hemorheol Microcirc 29:445-455

121. Koutsiaris AG, Pogiatzi A 2004 Velocity pulse measurements in the mesenteric arterioles of rabbits. Physiol Meas 25:15-20
122. Hickerson AI, Rinderknecht D, Gharib M 2005 Experimental study of the behavior of a valveless impedance pump. Exp Fluids 38:534-540

123. Huang H, Dabiri D, Gharib M 1997 On errors of digital particle image velocimetry. Meas Sci Technol 8:1427-1440

124. Sugii Y, Okuda R, Okamoto K, Madarame H 2005 Velocity measurment of both red blood cells and plasma of in vitro blood flow using high-speed micro PIV technique. Meas Sci Technol 16:1126-1130

125. Damiano ER, Long DS, Smith ML 2004 Estimation of viscosity profiles using velocimetry data from parallel flows of linearly viscous fluids: application to microvascular haemodynamics. J Fluid Mech 512:1-19

126. Smith ML, Long DS, Damiano ER, Ley K 2003 Near-wall u-PIV reveals a hydrodynamically relevant endothelial surface layer in venules in vivo. Biophys $J$ 85:637-645

127. Dabiri JO, Gharib M, Colin SP, Costello JH 2005 Vortex motion in the ocean in situ visualization of jellyfish swimming and feeding flows. Phys Fluids 17:091108.

128. Day SW, Higham TE, Cheer AY, Wainwright PC 2005 Spatial and temporal patterns of water flow generated by suction-feeding bluegill sunfish Lepomis macrochirus resolved by Particle Image Velocimetry. J Exp Biol 208:26612671 